e-ISSN: $1984-4255$ ARGUMENTOS

D01: $10.36517 /$ Argumentos.25.17

\title{
Tobias Barreto e as questões kantianas'
}

\section{Tobias Barreto and the Kantian issues}

\author{
Halwaro Carvalho Freire \\ https://orcid.org/0000-0002-5954-8439 - E-mail: halwarocf@yahoo.com.br
}

\begin{abstract}
RESUMO
Pouco citado e estudado nos currículos dos ambientes acadêmicos das universidades brasileiras, o filósofo sergipano, Tobias Barreto, foi um importante representante do Nordeste no que diz respeito a produção filosófica brasileira do século XIX. O seguinte artigo tem como objetivo expor algumas ideias deste pensador trazendo à luz a importância de se trabalhar um filósofo brasileiro num quadro em que predomina o estudo de filósofos ocidentais europeus. Assim, esse trabalho tem um duplo intento: "ressuscitar" algumas ideias do pensamento de Tobias Barreto e, ao mesmo tempo, mostrar a leitura e o diálogo que este autor buscou com a tradição que o precedeu, especialmente seu afastamento do positivismo de Auguste Comte e sua aproximação com a filosofia alemã, mais especificamente, com a leitura de Immanuel Kant.
\end{abstract}

Palavras-chave: Tobias Barreto. Positivismo. Kantismo. Criticismo.

\begin{abstract}
Little mentioned and studied in the curricula of the academic environments of Brazilian universities, the Sergipe philosopher, Tobias Barreto, was an important representative of the Northeast with regard to the Brazilian philosophical production of the 19th century. The following article aims to expose some of Tobias Barreto's ideas, highlighting the importance of working with Brazilian philosophers in a context in which the study of foreign Western philosophers predominates. Thus, this work has a double purpose: to "resuscitate" some ideas of the thought of Tobias Barreto and, at the same time, to show the reading and dialogue that

\footnotetext{
1 Esse trabalho é um resultado das pesquisas realizadas no Centro de Estudos em Filosofia Brasileira da Faculdade Católica de Fortaleza. Agradeço especialmente ao Evanildo Costeski o convite para a discussão em torno da temática que resultou nessa publicação. Este artigo também é fruto das discussões realizadas no Núcleo de Estudos Brasileiros da Universidade Federal do Ceará (NEB).
} 
this author sought with the tradition that preceded him, especially his departure from the positivism of Auguste Comte and his approach to German philosophy, more specifically, with the reading of Immanuel Kant.

Keywords: Tobias Barreto. Positivism. Kantism. Criticism.

\section{Introdução}

A introdução deste trabalho apresenta uma pequena síntese da biografia do autor Tobias Barreto. Concomitantemente, apontamos os primeiros passos dados pelo filósofo sergipano em direção à uma trajetória acadêmica. Feito isto, partiremos para uma exposição conceitual de algumas temáticas em que o Tobias Barreto se inseriu no quadro da história da filosofia do Brasil. Nascido na pequena vila de Campos, mulato, Tobias estudou as primeiras letras nessa mesma cidade e pouco tempo depois se dedicou a estudar a cadeira de Latim, em Estância. Apenas com 15 anos concluiu o curso de Latim e concorreu, no mesmo ano, 1854, para a vaga de professor substituto de Gramática Latina, onde conseguiu ser aprovado. Em 1859 recebeu uma licença de 6 anos, dada pela Assembleia Provincial, para realizar o curso de Direito fora de Sergipe. Contudo, antes de ir para Pernambuco, assistiu aulas de filosofia do Frei Itaparica até 1861, o que foi essencial para produção dos seus ensaios filosóficos. Apenas em 1862 Tobias Barreto viaja então para Pernambuco, para cursar Direito na Faculdade do Recife.

O lado poético de Tobias Barreto predominou na sua chegada em Recife ${ }^{2}$. Esse lado o insere como um dos representantes mais importantes da $3^{\circ}$ geração do romantismo, segundo Massaud Moisés (2006). Em 1868, Tobias Barreto estava terminando a faculdade de Direito e mantinha "disputas" com Castro Alves, daí o seu lado poético ter sido amplamente conhecido, como uma espécie de figura popular da época ${ }^{3}$. Dois fatores, aponta Paim, podem ter sido essenciais para levar Tobias a se interessar por Filosofia: ter sido aluno do Frei Itaparica, em 1861, como já mencionado, e a disputa da respectiva cadeira, no Ginásio Pernambucano, com o tomista Soriano de Sousa, em $1867^{4}$. Nessa época, havia no Brasil uma corrente de grande expressão: o ecletismo espiritualista. Esta corrente teve grande notoriedade no Brasil, principalmente pela figura de Silvestre Pinheiro Ferreira (1769/1846) e Victor Cousin (1793/1867). Destaca-se, aqui, o Curso de Filosofia que foi ministrado por Silvestre Pinheiro, publicado com o título de Preleções Filosóficas, reeditado pelo Instituto de Filosofia Brasileira (IBF), em 1970. Já, Victor Cousin, influenciou muitos brasileiros que viveram em Paris na década de trinta do século XIX. Era a doutrina filosófica mais ensinada nos cursos preparatórios (de Direito: em Recife

\footnotetext{
${ }^{2}$ Como afirma Luiz Antônio Barreto: "É o poeta que domina os primeiros anos de Tobias no Recife. Poeta inflamado, conclamando o povo para a luta, tendo como mote a guerra do Paraguai [...] Nas poesias do sergipano flui a convocação patriótica, que recebe do povo mais que o aplauso nas ruas, nos teatros, pelos locais públicos, a consagração literária, afirmando um talento que rivaliza com Castro Alves, poeta da Bahia, Vitoriano Palhares, poeta de Pernambuco, e outros jovens embriagados na beleza a arte poética". (BARRETO, 1994, p. 342).

${ }^{3}$ Sua chegada em Recife inflamou seu compromisso democrático. Tobias assumiu nas ruas a panfletaria, incentivando a coragem para lutar novamente, restaurando, assim, as pessoas que haviam passado por derrotas de 1817,1824 e 1848 . Tobias se mostrou neste sentido, um poeta social, que incentivava as massas com versos como este: "Patrícios, o drama é sério... Junto ao trono armas erguei, Nós mesmos somos o Império, Nós mesmos somos o Rei" (BARRETO, 1881, p. 155). O jornal O Americano, fundado por Tobias, demonstra também esse poeta social, uma vez que o referido jornal era uma tribuna aberta à propaganda abolicionista e republicana.

${ }^{4}$ Cf. Luiz Mercadante e Antônio Paim. Estudos de Filosofia. Tobias Barreto, part. 1 e 2. p. 07.
} 
e São Paulo; de Medicina: no Rio de Janeiro e em Salvador). Correspondia, assim, à filosofia oficial do Segundo Reinado.

Com a chamada geração de $70^{5}$, essa doutrina filosófica perdeu espaço devido ao grande número de críticas que recebe, salvo Tobias Barreto que, mesmo encampando as críticas proclamava ter-lhe despertado o gosto pelos estudos filosóficos (PAIM, 1999, p. 5). A década de 70 do século XIX produziu uma importante escola de pensamento surgida na Faculdade de Direito do Recife, denominada de Escola de Recife. Os representantes desta Escola elaboraram diversas críticas sob diversos aspectos: literário, filosófico, histórico, folclórico, poético e etc. ${ }^{6} \mathrm{~A}$ Escola do Recife constituiu um processo de diferenciação no seio do chamado surto de ideias novas, que consistiu em conduzir às últimas consequências o rompimento com o positivismo, trazendo à luz novos problemas para o debate filosófico no Brasil, onde se destacará Tobias Barreto 7 . Destaca-se, preliminarmente, que foi nesta década que houve o "despertar" de Tobias Barreto para questões filosóficas, uma vez que data de 1868 o seu primeiro artigo que dialoga com problemas filosóficos, a saber, "Guizot e a escola espiritualista do século XIX".

Em 1869, Tobias Barreto, teceu diversos comentários e articulou posicionamentos filosóficos de maneira mais clara. Direcionou suas críticas à escola de pensamento de Victor Cousin no Brasil e a tendência brasileira para o ecletismo espiritualista. Afirmou que a corrente de pensamento de Victor Cousin não passa de um novo gênero literário, vago, amorfo e indeciso (BARRETO, 1977, p. 75-101). Ao mesmo tempo, adotou uma espécie de positivismo moderado, que aderiu a escola de Augusto Comte no que diz respeito a postura crítica a teologia enquanto ciência, na mesma medida em que não se tornou um fiel discípulo ao afirmar que não sentiu pela metafísica em geral o profundo e sistemático rancor que pregava o positivismo (BARRETO, 1977, p. 99). Podemos dizer, assim, que, com apenas 30 anos, Tobias começou a assumir uma postura filosófica mais determinada, sendo a mesma caracterizada por uma crítica ao espiritualismo e, aderente, em determinados momentos, ao positivismo, mas tecendo críticas ao mesmo.

$\mathrm{O}$ ano em que Tobias Barreto se formou e tentou ganhar a vida como advogado em Recife foi 1870. Nesta década, o sergipano fundou um jornal, chamado, O Americano. Neste, Tobias, publicou vários artigos reunidos, com o título de Notas de Crítica Religiosa. Neste, é possível perceber o início do diálogo que o sergipano teve com representantes do hegelianismo9. Em 1875, Tobias retomou a crítica ao positivismo de Comte, tendo como interesse

\footnotetext{
${ }^{5}$ Formada predominantemente por jovens bacharéis egressos de Coimbra ou da Faculdade de Direito do Recife, dispostos a interferir na cena cultural com suas propostas e suas polêmicas, essa geração de escritores, tanto no Brasil como em Portugal, manifesta uma necessidade premente de decifrar, analisar, descrever e avaliar o ser português e o ser brasileiro. Tratava-se do mesmo movimento auto-analítico, fundamento e estratégia de um projeto político ambicioso (re)criar a nação -, cujo conteúdo crítico dirigia-se ao anacrônico sistema monárquico, aos modelos arcaicos de pensamento e de ensino e à produção e consumo de uma literatura, a romântica, considerada sentimental e escapista. Tanto a Geração de 1870 portuguesa, quanto a brasileira, indicavam a urgência em promover a superação dessas condições político-culturais para que se produzisse a renovação de suas respectivas sociedades, libertando-as da decadência, ou do atraso. (MOTA, 2013, p. 3).

${ }^{6}$ Nos limitamos aqui, apenas na análise no aspecto filosófico, representado por Tobias Barreto, nesta Escola. Destacamos que Silvio Romero na sua obra, Filosofia no Brasil, busca, com empenho refletir sobre as posições dos representantes dessa Escola. Para conhecimento de outros representantes importantes desta Escola. (Cf. ROMERO, 1878).

${ }^{7}$ Trataremos essa questão pormenorizada quando falarmos da relação entre positivismo e cultura no pensamento Tobisiano.

${ }^{8}$ Neste artigo, Tobias Barreto faz críticas ao ecletismo de Cousin, especialmente, ao método do psicológico do francês. Para o sergipano, tal método da escola espiritualista erra ao classificar e reduzir a leis os fatos internos da subjetividade. Assim, para o filósofo, o método da psicologia não pode ser idêntico ao método das ciências naturais, uma vez que "Aqui, as leis e forças da natureza são conhecidas, ou melhor, concebidas por meio da indução, com a precedência dos fatos particulares que se observam. Ali, pelo contrário, o eu que diz - penso, isto é, sinto, quero, conheço, movo-me etc., é uma força que se sente, que se conhece a si mesma" (BARRETO, 1977, p. 75).

9 Figuram em Crítica de Religião, Aracaju, Governo Estadual, 1978, p. 25-41 e no volume correspondente da edição das Obras Completas (1990). Sobre tais notas diz Paim: Apreciando esta primeira polêmica, escreve Clóvis Beviláqua: "A Crônica dos Disparates" interessa mais à história das ideias da Faculdade de Direito, por ser uma polêmica entre Autran, antigo lente, representante das velhas ideias católicas e tomistas, e Tobias, recém-formado, futuro lente, representante do espírito novo, que começava a invadir
} 
principal "ressuscitar" a metafísica. Tendo como norte uma nova roupagem para a metafísica, o filósofo sergipano influenciou-se, de maneira inicial, na obra de Ernest Haeckel do período mecanicista ${ }^{10}$, tendo em vista especialmente o livro História Natural da Criação (1868). Embora concordasse, em parte, com a teoria de Haeckel ${ }^{11}$, uma vez que, para o sergipano, este teria dado um passo à frente em relação ao positivismo, pois seu monismo abriu espaço para uma intuição geral do universo, é apenas com a leitura do filósofo alemão Immanuel Kant que a sua postura no que se refere à metafísica dará um "giro copernicano". Foi no ensaio "Recordações de Kant" que Tobias Barreto desenvolveu a tese de que o objeto próprio da filosofia seria a teoria do conhecimento. A grande contribuição de Kant, para o sergipano, foi, assim, o estudo da razão humana.

Outro ponto relevante na trajetória filosófica de Tobias Barreto foi o conceito denominado por ele de culturalismo. O sergipano apontava a cultura como o sistema de forças na luta pela humanização da vida. Afirmava que a vida social é a verdadeira vida do homem, que se constituía de formas conscientes. Se tais formas conscientes pudessem igualmente ser chamadas de seleção, caberia falar de uma "seleção jurídica, a que se pode adicionar a religiosa, moral, intelectual e estética, todas as quais constituem um processo geral de depuramento, o grande processo da cultura humana". Assim, continua Tobias Barreto, "a sociedade, que é o domínio de tais seleções, pode bem se definir: um sistema de forças que lutam contra a própria luta pela vida" (BARRETO, 1887, p. 3-4). E, destarte, a sociedade, que é o domínio de tais seleções, pode bem se definir: um sistema de forças que lutam contra a própria luta pela vida" (BARRETO, 1887, p. 4). Assim, aponta Paim, "pode-se concluir que Tobias Barreto não só propugnou pela abordagem da cultura de um ponto de vista filosófico, como a considerou numa relação superadora da natureza - e portanto dialética" (PAIM, 1995, p. 30).

\section{O retorno à metafísica a partir de Kant}

Depois da apresentação, na introdução, dos principais tópicos discutidos por Tobias Barreto durante sua trajetória de vida, iremos focar, a partir de agora, no diálogo que o autor sergipano teceu com a filosofia do alemão, Immanuel Kant. Apesar do encontro tardio com a filosofia kantiana, em 1887, é a teoria do conhecimento do pensador de Königsberg que despertou o sergipano e o serviu, por assim dizer, como "munição" para enfrentar o positivismo. ${ }^{12}$

O distanciamento de Tobias Barreto do positivismo se dá por conta da metafísica, escreve o autor sergipano:

Os positivistas não querem compreender que uma coisa é a metafísica dogmática, que converte sonhos em realidade, que fecha os olhos para melhor ver, que desdenha da experiência, quando esta vai de encontro aos seus oráculos, e outra coisa é a metafísica

o país... Autran orçava pelo sessenta e cinco anos e escrevia no "Católico", periódico destinado à defesa das ideias da religião dominante" (1999, p. 15).

10 Afirma Haeckel (1834/1919) "A nossa concepção monista do universo pertence pois a esse grupo de sistemas filosóficos que se designam, sob um outro ponto de vista, com os nomes de mecanistas ou panteístas. Por mais diferentemente que sejam expressas nos sistemas de um Empédocles e de um Lucrécio, de um Spinoza ou de um Bruno, de um Lamarck ou de um Strauss, subsistem, no entanto, as idéias fundamentais comuns da unidade cósmica, da solidariedade inseparável da força e da substância, do espírito e da matéria ou, como também se pode dizer, de Deus e do mundo" (HAECKEL, 1908, p. 5).

11 Sobre isso, ver (BARRETO, 1977, p. 205-216).

12 Segundo Carvalho (2017, p. 94): A descoberta de Kant pelos intelectuais brasileiros remonta aos primórdios do século XIX depois da popularização da obra de Charles Villers intitulada Filosofia de Kant ou princípios fundamentais da filosofia transcendental, de 1801. A divulgação dessa obra foi atribuída a Francisco Bento Maria Targini, Visconde de São Lourenço, que acompanhou D. João VI e a corte para o Rio de Janeiro (CARVALHO, 2017, p. 94). Sobre a entrada do kantismo no Brasil, ver também (PAIM, 1997, p. 440). 
reservada e consciente, que há de sempre existir, se não como ciência, como disposição natural e inerradicável do espírito, segundo Kant. (BARRETO, 1977, p. 386).

Percebe-se claramente que a leitura de Tobias Barreto sobre Kant tem como ponto de partida a insatisfação do sergipano tanto com o monismo como com o positivismo. As teses monistas, já mencionadas em nossa introdução, "ferem" diretamente um pressuposto necessário à filosofia transcendental kantiana, uma vez que formula hipóteses sobre a coisa em si, o que ultrapassa os limites da experiência possível ${ }^{13}$. Já o positivismo, para Tobias, daria um terreno mais seguro na formação do conhecimento, contudo, escaparia desta corrente as questões metafísicas. A filosofia transcendental aparece, assim, como a teoria que é capaz de fundamentar o campo da ciência, ao mesmo tempo, em que resguarda espaço para as questões inevitáveis da razão ${ }^{14}$, as ideias metafísicas. Tobias Barreto, em A religião perante a psicologia, publicado em 1870, no Jornal O Americano, afirma que, para Augusto Comte, há três momentos sucessivos do pensamento humano: o teológico, primeiro estágio desse processo, o metafísico, que seria superado pelo terceiro momento, o positivismo científico (BARRETO, 1977, 179). Se Comte admite esses três momentos sucessivos, é que para ele a metafísica não tem positividade, não oferece garantia contra os assaltos da dúvida, não passa de um fascículo de abstrações e inverificáveis hipóteses.

Compreendemos que o que marcou também o afastamento de Tobias do positivismo foi o escrito Sobre a filosofia do inconsciente, de 1874. Contudo, possivelmente esse texto não chegou a ser concluído pelo pensador sergipano, sendo divulgado por Silvio Romero em Estudo Alemães. Há uma passagem interessante em que Tobias disserta sobre o estudo do inconsciente desenvolvido por Eduard Von Hartmann, declara o pensador sergipano:

O Schopenhauerismo é uma metafísica da vontade, a quem exclusivamente o filósofo confere o primado universal. Como, porém, na natureza a vontade opera de uma maneira cega, isto é, sem consciência, e a ideia não aparece para conhecer sua imbecilidade, senão muito depois, imaginou Von Hartmann fazer do inconsciente o objeto de uma filosofia. E com efeito erguem sobre este plano um verdadeiro monumento do gênero (BARRETO, 1977, p. 288).

Nota-se na passagem acima que Tobias direciona seu afastamento do positivismo de Comte, uma vez que este não abria espaço para o "primado do universal". Consideramos que foi esse distanciamento da objetividade científica e da recusa do ecletismo espiritualista ${ }^{15}$ que aproximou Tobias ao pensamento kantiano. Ora, é a filosofia de Kant que proporciona uma espécie de "meio termo", entre o ecletismo espiritualista e a objetividade positivista. Kant compreende a filosofia como uma "estrutura" composta de várias partes onde as mesmas são relacionadas entre si, é o que Kant denomina de unidade sistemática ${ }^{16}$. É neste modelo arquitetônico

\footnotetext{
${ }^{13} \mathrm{~A}$ filosofia transcendental é aquela que "considera apenas o entendimento e a própria razão num sistema de todos os conceitos e princípios que se referem a objetos em geral, sem pressupor objetos que fossem dados (ontologia)" (CRP, A 845 B 873). Assim, em outra passagem, afirma Kant: "chamo de transcendental todo conhecimento que se ocupa em geral, não tanto de objetos, mas de nosso modo de conhecimento de objetos na medida em que esse deve ser possível a priori" (CRP B25).

14 Já no prefácio da primeira edição da Crítica da razão pura (1781), Kant descreve a razão humana como possuidora de um "singular destino" e que, por isto, encontra-se constantemente "atormentada por questões que não pode evitar, pois Ihe são impostas pela sua natureza" (CRP, A VII).

15 Sobre a influência do ecletismo francês no Brasil, declara Tobias Barreto: "O mundo filósofo, não menos que o mundo moral e político, também conta seus ridículos. A parte cômica da filosofia pertence hoje aos diretos descendentes de Cousin. $O$ espiritualismo de Franck, Simon, Caro, Amédée de Margerie, e muitos outros, que não passa de um estéril e misérrimo comentário do credo católico, é um dos trejeitos de repugnância que ainda faz o século XIX, diante da taça cheia de novas e acérrimas verdades, que the oferece a mão dos grandes pensadores" (BARRETO, 1977, p. 185).

${ }^{16}$ Afirma Kant: "Como a unidade sistemática é o que converte o conhecimento vulgar em ciência, isto é, transforma um simples agregado desses conhecimentos em sistema, a arquitetônica é, pois, a doutrina do que há de científico no nosso conhecimento em geral e pertence, assim, necessariamente, à metodologia" (CRP, A 832 B 860).
} 
da razão pura, que legitima seus conhecimentos e que abre espaço para as questões inevitáveis (metafísica), que Tobias encontra o que buscava, uma renovação da metafísica em relação com o pensamento científico. Afirma o sergipano em A religião perante a psicologia, de 1870:

A verdade não é o único pão de que o espírito se alimenta; a verdade não é a única medida das coisas. Quando este paradoxo penetrar em nossas crenças, acabar-se-ão muitas lutas, porque a lógica saberá conter-se, e não quererá dar leis nos domínios alheios (BARRETO, 1977, p. 189).

Tobias entende, assim, que voltar a Kant é progredir. Admite que em seu período nenhum homem verdadeiramente culto deveria ignorar que o dogmatismo da metafísica moderna foi abalado por Hume, cuja implacável crítica coube a Kant concluir em largas proporções e com mais considerável profundeza (BARRETO, 1977, p. 135). O sergipano chega a afirmar que "toda a filosofia até o aparecimento de Kant [...] não passou de um sonho estéril de falsidades e servilismo intelectual" (BARRETO, 1977, p. 136) do qual os novos tempos foram libertados por meio da Crítica da Razão Pura ${ }^{17}$. Tobias fez uma leitura muito precisa das influências que marcaram a filosofia kantiana, uma vez que declara que "foram principalmente Wolf, Locke e Hume que indicaram os marcos capitais por onde Kant teve de passar antes de descobrir os seus próprios" (BARRETO, 1977, p. 136).

Provavelmente se referindo aos positivistas, mas não nomeando-os, Tobias declara que estes queriam fazer da metafísica um artigo de "puro contrabando espiritual" sem notar que os que se abstém dessa "mercadoria" são, ao mesmo tempo e em grande medida, consumidores inconscientes de uma ou de outra de suas inúmeras falsificações (BARRETO, 1977, p. 137). Ora, o filósofo sergipano faz referência às questões inevitáveis da razão humana, as questões metafísicas, e se remete, assim, ao papel fundamental da primeira Crítica de Kant, a saber, delimitar e legitimar os princípios que constituem um conhecimento válido e objetivo frente ao seu método de investigação ${ }^{18}$. As questões metafísicas abordadas pelo ecletismo espiritualista iam, assim, na contramão da Crítica elaborada por Kant, uma vez que, e Tobias endossa, transformava o domínio suprassensível num teatro de disputas infindáveis ${ }^{19}$. É neste sentido que Tobias estudava Kant, para combater os exageros do ecletismo e das objetivações do positivismo, evidentemente, tendo em vista a produção de uma filosofia brasileira que refletisse sobre os problemas do país e não um mero comentário exegético dos textos de estrangeiros. É neste viés que interpreta, por exemplo, Marcondes Constança ao dizer que: "Para Tobias Barreto, a solução

\footnotetext{
${ }^{17}$ Tobias Barreto estudou profundamente a língua alemã, como podemos notar no seguinte comentário de Clóvis Beviláqua (1927, p. 104): Dedicando-se ao estudo da língua e da literatura alemãs, a impressão primeira de Tobias foi a do deslumbramento pelas opulências apenas entrevistas até então, e agora diretamente conhecidas. Depois o germanismo tornou-se forma de sua organização espiritual, conquistando-Ihe fortes simpatias na Alemanha e fortes increpações no Brasil. Vamireh Chacon (1959, p. 82) declarou certa vez ter encontrado setenta e nove livros, "num total de cento e dois volumes em alemão, da antiga biblioteca Tobias Barreto, vendida à Faculdade de Direito do Recife". Tobias contava ainda, por exemplo, com dois volumes da obra de Karl Marx em sua biblioteca. A indicação de Vamireh Chacon: Marx, Karl, Das Kapital, Kritik der politischen Oekonomie, Hamburg: Otto Meissner, 2 volumes, 1883-1885. A formação da biblioteca do sergipano nos dá indício do peso que a filosofia alemã tinha para ele quando o mesmo investigava os problemas do Brasil do final do século XIX.

${ }_{18}$ Para Kant, a razão, por meio de um processo natural, ao buscar a completude absoluta de condicionado em condicionado, ela mesma produz ideias transcendentais, conceitos absolutamente incondicionados, puramente metafísicos.

${ }_{19}$ Declara Kant na seguinte passagem: Não é por culpa sua que cai nessa perplexidade. Parte de princípios, cujo uso é inevitável no decorrer da experiência e, ao mesmo tempo, suficientemente garantido por esta. Ajudada por estes princípios eleva-se cada vez mais alto (como de resto lho consente a natureza) para condições mais remotas. Porém, I logo se apercebe de que, desta maneira, a sua tarefa há-de ficar sempre inacabada, porque as questões nunca se esgotam; vê-se obrigada, por conseguinte, a refugiar-se em princípios, que ultrapassam todo o uso possível da experiência e, não obstante, estão ao abrigo de qualquer suspeita, pois o senso comum está de acordo com eles. Assim, a razão humana cai em obscuridades e contradições, que a autorizam a concluir dever ter-se apoiado em erros, ocultos algures, sem, contudo os poder descobrir. Na verdade, os princípios de que se serve, uma vez que ultrapassam os limites de toda a experiência, já não reconhecem nesta qualquer pedra de toque. $O$ teatro destas disputas infindáveis chama-se Metafísica (CRP, A VIII).
} 
não consistiu numa simples volta a Kant, mas em inspirar-se em Kant, apontando novos caminhos à reflexão e respondendo à crise filosófica do final do século passado" (CESAR, 1991, p. 105). Vejamos, agora, como a epistemologia "serve" a Tobias Barreto como uma "luva" para as questões e os problemas que estava refletindo sobre o Brasil.

\section{A Filosofia como epistemologia na visão de Tobias Barreto}

A epistemologia de Kant influenciou diretamente o pensamento de Tobias Barreto no que se refere aos objetos da Filosofia, concebidos por este último autor. Tobias ressalta a importância de conceber uma ciência que considere a matemática, a física, a experiência como seus objetos, da mesma forma que a matemática tem por objeto as grandezas, a física os corpos, a experiência as coisas em geral (BARRETO, 1977, p. 380). Afirma o autor sergipano:

[...] Dá-se porventura que a matemática, a física, a experiência expliquem-se por si mesmas? Se não se explicam deve haver então uma ciência distinta e autônoma, que esteja para a matemática como esta para as grandezas, que esteja para a física, como esta para os corpos, que esteja enfim para toda a experiência, como esta para os fenômenos dados. Esta ciência tão necessária como as outras, é a filosofia crítica, é a metafísica, no bom sentido de expressão (BARRETO, 1977, p. 156).

O que o autor tem em mente, neste sentido, é o papel fundamental que a Filosofia tem em relação a ciência, é a primeira que pensa os pressupostos que a última utiliza em seu saber. Assim, a filosofia não aumentaria o saber científico, mas teria como missão compreendê-la. Tobias colocou a filosofia crítica como a filosofia do futuro, como uma renovação no campo filosófico de sua época que foi, ainda para o autor, dignamente iniciada pelos trabalhos de Hartmann, Noire, Spir, Fortlage e outros (BARRETO, 1977, p. 386). A filosofia crítica de Kant se apresentou para Tobias como uma ciência dos limites da razão humana (eine Wissenschaft von den Grenzen der menschlicken Vernun). Para o autor, restou somente que os espíritos, para quem "a filosofia não é assunto de entretenimento banal, mas uma das mais nobres ocupações do pensamento humano, saibam aproveitar-se do exemplo e da ligação dos mestres" (BARRETO, 1977, p. 386).

O tema do conhecimento, desta maneira, não se restringiria aos limites da fisiologia e da psicologia, mas achava sua razão de ser com a filosofia. Artur Orlando, pessoa que teve contato direto com Tobias Barreto na fase final da vida do sergipano destacou a contribuição do neokantismo para a superação das limitações do positivismo. Para o autor, não devemos esquecer que a filosofia, em sua época, já não queria dizer ciência do absoluto, nem explicação do universo "nem qualquer dessas grandes sistematizações conhecidas pelos nomes de seus autores (darwinismo, comtismo, spencerismo), mas teoria do conhecimento [...] sobre a qual se apoiam todas as ciências" ${ }^{\prime 20}$. Clovis Bevilaqua reconhece em Tobias Barreto também um admirador e propagador da filosofia crítica no Brasil, escreve:

O kantismo em sua feição nova, abeberado do pessimismo tentador de Schopenhauer, condimentado pelo idealismo cético de Lange e Hume, e combinado com o transformismo darwinico pelos esforços de Noiré, teve no Brasil quem lhe consagrasse a elevada potência de seu engenho e as vibrações, muitas vezes ásperas, do seu temperamento de lutador. Foi Tobias Barreto, cujo merecimento como renovador da ciência jurídica entre nós, não deve atabafar o seu valor como ensaísta filosofante dos mais conspícuos (BEVILAQUA, 1899, p. 35).

\footnotetext{
${ }^{20}$ Há várias notas à introdução ao livro de Tobias Barreto, Questões vigentes, de 1888, ao republicá-la com o título de "Tobias Barreto" (Ensaios de crítica, Recife, 1904. Ver Ensaios de crítica, São Paulo, USP, 1975, p. 93-97).
} 
Silvio Romero encontra-se nessa mesma linha interpretativa. Para o autor, a tendência filosófica principal de sua época na Alemanha, França, Inglaterra, Itália e Espanha estava justamente no criticismo, espécie de neokantismo, por tomar-lhe o espírito, nesse sentido, o moderno “Ess muss auf Kant zurückgegangen werden" é verdadeiro (BEVILAQUA, 1899, p. 35).

Tobias toca diretamente no ponto crucial da filosofia transcendental, a fundamentação das condições de possibilidade da experiência ${ }^{21}$. Para o sergipano, a filosofia de Kant não teve como destino aumentar o número dos nossos conhecimentos por meio do pensar puro, porquanto o princípio supremo é que toda e qualquer noção de realidade deve ser bebida pela experiência, mas, diz Tobias, "o seu único intuito foi o de inquirir as fontes de nosso saber e o grau de sua legitimidade, trabalho este, que há de sempre pertencer à filosofia" (BARRETO, 1977, p. 371).22 A compreensão de Tobias em relação a filosofia transcendental não para por aí, Carvalho afirma que "ao adotar a posição de Kant, Tobias esperava contornar o relativismo epistemológico do empirismo inglês que critica no ensaio A relatividade de todo conhecimento" (CARVALHO, 2017, p. 97). Como afirma o sergipano na seguinte passagem:"É na Inglaterra, principalmente, que, nos últimos tempos, a teoria da relatividade do saber tem sido professada e discutida com particular predileção" (BARRETO, 1977, p. 311). Para Carvalho (2017, p. 98), Tobias recusa do empirismo a tentativa de eliminar a liberdade, o que se comprova com a seguinte passagem de Variações anti-sociológicas: "os modernos contraditores da liberdade, os que pretendem mecanizá-la e destruí-la filiam em geral à escola de Hume" (BARRETO, 1977, p. 322). Tobias Barreto tece, assim, um diálogo com Kant em busca de uma legitimação do conhecimento, que resguarde a esfera da liberdade. ${ }^{23}$

\section{Considerações finais}

Este artigo buscou retratar a importância do pensamento do filósofo sergipano Tobias Barreto para a história das ideias filosóficas do Brasil. Partimos, já na introdução, para uma descrição da trajetória de vida deste pensador, tendo em vista que os encontros que ele teve ajudou-o a formar o pensamento filosófico. Vimos que Tobias, passou por grandes dificuldades financeiras e que o seu lado intelectual floresceu ainda muito novo. Dono de uma oratória e de um vasto domínio linguístico, ressaltou-se o latim e o alemão, o sergipano deu seus primeiros passos na poesia, o que levou para sua maneira de fazer filosofia.

Percebemos que o encontro deste autor com o Frei Itaparica, em 1861, foi indispensável para que o poeta social, que defendia movimentos abolicionistas e feministas na época, levasse sua expressão poética para a reflexão filosófica. Inserido num Brasil de correntes filosóficas que pregava o ecletismo espiritualista de um lado e o positivismo científico do outro, Tobias se sos-

\footnotetext{
${ }^{21}$ Para Kant, o sujeito é constituído por uma receptividade, que é a capacidade de receber representações, mediante a maneira pela qual somos afetados pelos objetos (CRP, A 19 B 33); e por uma espontaneidade, que é a capacidade de produzir representações (CRP, A 51) B 75 . Sobre a receptividade encontra-se a faculdade da sensibilidade e sobre a espontaneidade se expressa a faculdade do entendimento. Pela primeira faculdade (sensibilidade) temos as intuições, nas quais é dado um objeto. Pela segunda (entendimento) temos os conceitos, nos quais o objeto é pensado. Deste modo, sem a sensibilidade, não poderíamos intuir nenhum objeto; e sem o entendimento nenhum objeto seria pensado. O sujeito é constituído, portanto, por intuições e conceitos, de modo que só pela sua reunião se obtém conhecimento

${ }^{22}$ Essa passagem mostra a precisão e a leitura da filosofia de Kant por parte do filósofo sergipano. Afirma Kant já na Introdução: Não resta dúvida de que todo o nosso conhecimento começa pela experiência; efetivamente, que outra coisa poderia despertar e pôr em ação a nossa capacidade de conhecer senão os objetos que afetam os sentidos e que, por um lado, originam por si mesmos as representações e, por outro lado, põem em movimento a nossa faculdade intelectual e levam-na a compará-las, ligá-las ou separálas, transformando assim a matéria bruta das impressões sensíveis num conhecimento que se denomina experiência? (CRP, B1).

${ }^{23}$ Para fins desse artigo, não tocaremos na análise feita por Tobias Barreto sobre a Filosofia Prática kantiana, isso nos desviaria para um outro campo de argumentação, que fugiria do tema aqui proposto.
} 
bressaiu, conseguindo assumir uma posição até então inovadora, um retorno à metafísica, ao mesmo tempo, em que resguardava o conhecimento positivista nas ciências da época, física, matemática, biologia e etc.

Constamos que foram essas questões que levaram Tobias ao encontro do pensamento alemão, passando por Koiré, Eduard Von Hartmann, até chegar a Kant. O sergipano encontrou na filosofia kantiana as bases para pensar uma epistemologia que não anulava o empirismo humeano, admirado pelo autor como àquele que abalou a pretensão teológica em objetivar as questões metafísicas, por um lado, e lhe deu "ferramentas" contra o positivismo no âmbito da tendência desta corrente em querer anular o papel da Filosofia na construção do conhecimento. Obviamente, muito mais se poderia falar sobre Tobias Barreto, contudo, procuramos destacar neste trabalho a grandeza de um pensador, mulato, nordestino, num Brasil profundamente marcado, principalmente em sua época, por uma discriminação racial fortíssima. $O$ poeta social e filósofo, com tantas adversidades, conseguiu tecer diálogos com a tradição filosófica ocidental e o mais importante, conseguiu pensar os problemas do Brasil.

\section{Referências}

BARRETO, L. Tobias Barreto. Aracaju: Sociedade Editorial de Sergipe, 1994.

BARRETO, T. Estudos de Filosofia. São Paulo: Grijalbo, 1977.

BARRETO, T. Dias e Noites. Rio de Janeiro: Imprensa Industrial, 1881.

BEVILAQUA, C. Esboços e fragmentos, Rio de Janeiro: Laemmert, 1899.

BEVILAQUA, C. História da Faculdade de Direito do Recife. Vol. II. Rio de Janeiro: Livraria Francisco Alves, 1927.

BRAZ TEIXEIRA, A. A filosofia jurídica do século XIX. Lisboa: Humus, 2011.

CARVALHO, J. A Filosofia Culturalista de Tobias Barreto, a retomada do kantismo. Annales, v. 2, n. 3, 2017.

CARVALHO, J. A filosofia culturalista do direito de Tobias Barreto. In: Atas do X Colóquio Tobias Barreto. Lisboa: MIL. 2016.

CARVALHO, J. Antologia do Culturalismo Brasileiro, um século de filosofia. Londrina: EDUEL, 1998.

CESAR, C. A metafísica de Tobias Barreto. In: Atas do I Colóquio Tobias Barreto. Lisboa: Fundação Calouste Gulbenkian, 1991.

CHACON, V. A sociologia e o germanismo segundo Tobias Barreto e Silvio Romero. Revista Doxa, v. 5, n. 8, 1959.

GUIMARÃES, A. Tobias Barreto e o cientificismo de sua época. In:Atas do / Colóquio Tobias Barreto. Lisboa: Fundação Calouste Gulbenkian, 1991.

HAECKEL, E. História Natural da Criação. Trad. F. Cardoso. Versão para ebook. Livraria Chardon: Porto, 1908.

KANT, I. Crítica da razão pura. (ed. A e B). Trad. M. dos Santos e A. Morujão. 7. ed. Lisboa: Fundação Calouste Gulbenkian, 2010.

MOISES, M. A criação literária. São Paulo: Cultrix, 2006.

MOTA, M. A Geração de 1870 e a invenção simbólica do Brasil. Anpuh. Natal. 2013. 
PAIM, A. A evolução de Tobias Barreto e seu significado para a filosofia brasileira. In: Atas do I Colóquio Tobias Barreto. Lisboa: Fundação Calouste Gulbenkian, 1991, p. 21-32.

PAIM, A. A problemática do culturalismo. Porto Alegre: Edipucrs, 1995.

PAIM, A. História das ideias filosóficas no Brasil. Londrina: EDUEL, 1997.

PESSOA, L. Aspectos do Pensamento Alemão na Obra de Tobias Barreto. São Paulo: USP, 1985.

ROMERO, S. A Filosofia no Brasil. Porto Alegre: Typ. de Deutsche Zeitung. 1878.

ROMERO, S. A literatura brasileira e a crítica moderna. Ensaio de generalização. Rio de Janeiro: Imprensa Industrial de João Ferreira Dias, 1880.

ROMERO, S. O Brasil na primeira década do século XX. Lisboa: Tip. de "A Editora”, 1911.

\section{Sobre o autor}

Halwaro Carvalho Freire

Doutor em Filosofia pela Universidade Federal do Ceará (UFC). Professor da Faculdade Católica de Fortaleza (FCF).

Recebido em: 27/04/2020.

Received: 27/04/2020.

Aprovado em: 28/06/2020.

Approved: 28/06/2020. 